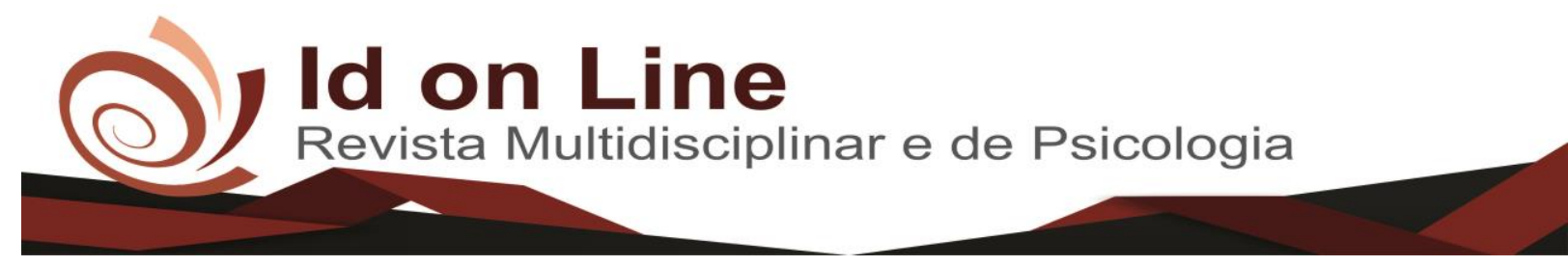

Artigo

\title{
Custeio Variável: Uma Ferramenta de Auxilio na Tomada de Decisão Gerencial
}

\author{
Maria Edileide Ferreira de Sousa ${ }^{1}$; Francisca Alexssandra de Macedo Anastácio ${ }^{2}$
}

\begin{abstract}
Resumo: Diante do atual cenário competitivo onde o empreendedor tem que saber enfrentar os grandes desafios em um ambiente de constante mudanças competitivas, sente-se cada vez mais a necessidade de alagar seus horizonte com visão estratégica para obter vantagens.Sendo assim referido estudo busca demonstrar a importância do sistema de custeio variável como ferramenta para auxiliar os gestores nas tomadas decisões, uma vez que conhecer o custo é uma condição essência para empresa, independente do tipo,logo á analise e o gerenciamento dos custos garante a sobrevivência de qualquer organização.Dessa forma o sistema de custeio é uma ferramenta para potencializar o processo de melhorias na tomada de decisões uma vez que a contabilidade de custo é um instrumentos gerencial capaz de auxiliar,controlar e planejar as decisões a serem tomada, contribuindo satisfatoriamente na estratégica profissional e possibilitando de maneira geral a devida qualidade das informações que seram utilizadas para mensurar os custos incorridos, conseguindo assim atingir vantagens competitivas,já que é capaz de desenvolver novas estratégica para reduzir dispedicios sempre na busca de informações para otimizar os custos.
\end{abstract}

Palavra-Chave: Custeio Variável.Ferramenta Estrategica .Vantagens Competitiva

\section{Variable Costing: A Tool to Help in Decision Making}

Abstract: Given the current competitive scenario where the entrepreneur has to know how to face the great challenges in an environment of constant competitive changes, there is an increasing need to expand his horizon with a strategic vision to obtain advantages. the importance of the variable costing system as a tool to assist managers in making decisions, since knowing the cost is an essential condition for a company, regardless of the type, then the analysis and cost management guarantees the survival of any organization. the process of improvements in decision making since cost accounting is a managerial tool able to assist, control and plan the decisions to be made, contributing satisfactorily to the professional strategy and enabling the quality of the information which will be used to measure the costs incurred, thus achieving competitive advantages, since it is able to develop new strategic to reduce disruptions always in the search of information to optimize costs.

Keyword: Variable Costing. Strategic Tool. Competitive Advantages

\section{Introdução}

A contabilidade de custos de grande importância para o planejamento e controle e gerenciamento de qualquer organização, visto que o atual mercado cada vez mais competitivo,

\footnotetext{
${ }^{1}$ Graduanda no curso de Ciências Contábeis no Centro Universitário Doutor Leão Sampaio. Juazeiro do Norte, Ceará. E-mail: edileidesousapires@gmail.com;

${ }^{2}$ Professora.Orientadora. Centro Universitário Doutor Leão Sampaio - UNILEÃO. Especialista em Economia, Gestão, Administração e Matematica,financeira. E-mail:alexsandraanastacio@leãosampaio.edu.br 
os gestores são obrigados a buscarem instrumentos gerenciais adequados capazes de enfrentar os grandes desafios em um ambiente de constantes mudanças,adaptando-se as transformações com maior agilidade por parte das administradores de soluções rápidas no gerenciamento de atividades empresariais para o processo de tomada de decisão, e especialmente para atender as necessidades dos clientes, dessa forma conseguir atingir vantagens frente aos concorrentes.

Portanto para adaptar-se as transformações e conseguir trazer retorno lucrativo é indispensável que os gestores adotem um sistema de custeamento para definir com maior precisão os custos de produção,e dessa forma através das informações será possível aplicar uma margem de lucro que resulte em preços que sejam, simultaneamente competitivos,( CREPALDI 2013)

Tomando por base esse mercado competitivo, com consumidores cada vez mais exigentes em termos de qualidade de produtos,e sempre visando o menor custo beneficio ofertado, as empresas passam a aprimorar constantemente os seus métodos de gestão. Para tanto, estas decisões necessitam estar fundamentadas em elementos confiáveis e concisos para nenhum destes atos venha prejudicar a estabilidade da entidade.A contabilidade de custos é uma das particularidades da contabilidade geral que é empregada no âmbito empresarial além de dar a oportunidade aos seus usuários de avaliar um produto e os valores associados a ele.Logo,a abordagem concedida aos custos interfere diretamente no preço de venda e, por decorrência, no resultado da empresa.

“A organização que não aprender a se adaptar as mudanças não obterá vantagens competitivas, mas aquela que aprender a explorar as oportunidades que as mudanças provocam possuirão subsídios fundamentais para se tornar competitiva no mundo da inovação" (HASHIMOTO, 2006, p.114).

O conhecimento em relação aos processos se torna indispensável para análise dos custos dos produtos, seja ele unitário ou total. Partindo desse cálculo dos custos pode-se dizer que a empresa estará sendo norteada em relação a chegar ao preço do produto. O presente trabalho visa expor o controle de custos no que diz respeito à formação de preços, pois é uma das dificuldades encaradas pelos gestores e encontrada em maior parte das corporações, que é estabelecer o preço correto, de modo que a entidade possa arcar com todas as suas despesas e custos e, inclusive, ainda poder obter lucro. Logo é necessário compreender os dados e a estrutura que constituem esta formação.

O presente artigo foi desenvolvido através de pesquisa bibliográfica buscando em literatura focando na área de custos e de gerenciamento estratégicos e com abordagem qualitativa , elaborado coma finalidade de mostrar a importância do sistema de custeio variável 
,onde seus objetivo é demonstrar a importância do sistema de custeio variável para as organização, apresentando dessa forma como o sistema de custeio pode suprir as informações precisas sobre o controle de custos . E dessa forma apresentar as decisões que deve ser tomada baseado em informações, proporcionando melhorias à empresa, focando na identificação dos custos, para posteriormente serem reduzidos sem afetar a qualidade do produto ofertado.

\section{Fundamentação Teórica}

\section{Contabilidade de Custo}

Conforme Martins (2010), a Contabilidade de custo surgiu da contabilidade financeira, quando sentiu a necessidade de avaliar estoque na indústria , tarefa essa que era fácil na empresa típica da era mercantilismo, pois “Até a Revolução Industrial (século XVIII), quase só existia a contabilidade financeira (ou Geral)" (MARTINS 2010,p.19).

Ainda segundo Martins (2010), com o surgimento da indústria a missão do contador tornou-se ainda mais complicada, já que possuía dados suficiente para conseguir distribuir valores para os estoques, pois aos valores da compras nas empresas comerciais foram acrescentado por uma série de valores pagos pelo fatores de produção utilizada. Logo os contadores tiveram que adaptar as empresas industrial os mesmo critérios utilizados nas empresas comercias. A preocupação primeira dos Contadores, Auditores e Fiscais foi a de fazer da Contabilidade de Custo uma forma de resolver seus problemas de mensuração monetária dos estoques e do resultado, não a de fazer dela um instrumento de administração (MARTINS 2010,p.21)

Para Bornia (2010), o desenvolvimento das empresa e conseguentemente, a produção ,fez com que os contadores buscassem suporte capaz resolver seus problemas de mensuração, para assim registrar as informações fornecidas pelas as organizações com a finalidade de atribuir um valor ao estoque.

Ainda conforme Bornia (2010), a Contabilidade de Custo essencialmente, tem como proposito estabelecer meios para a apuração do custo dos estoques possibilitando desse modo a determinação do resultado da empresa pela a contabilidade financeira. Assim o sistema de custo precisa estar interligado com a contabilidade financeira, possibilitando assim maior segurança na informação. 
Assim como para Stark (2007), a contabilidade de custo é classificada como uma ferramenta capaz de atingir finalidade específica, já que consegue determinar a rentabilidade e avaliação do patrimônio através dos dados fornecidos sobre os custos de produção de cada produto produzido ou comercializados.

Oliveira (2013) Afirma que a condição para permanência das empresas depende do gerenciamento dos custos, tendo em vista que a carência de informação dos custos incapacita os gestores de apresentar informações precisas para a tomada de decisões acertadas, uma vez que a análise e gerenciamento dos custos garante a sobrevivência de qualquer organização no atual cenário competitivo. Assim, o sistema de custeio visam auxiliar os usuários a tomar decisões precisas e eficaz, que contribuão com o comprimento das atividades do controle e planejamento. (CORONETTI E SOUZA 2012). Neste contex to o sistema disponibilizado pela contabilidade de custo tem como finalidade fornecer aos usuários informações necessárias para a tomada de decisão.

Para CREPALDI (2013, p.83), ”o custeio representa um elemento essencial das atividades de contabilidade gerencial das empresa", logo a contabilidade de custos nos dias atuais pode ser uma importante aliada á sobrevivência de qualquer organização.

\section{Nomeclatura e Classificação dos Custos}

\section{Nomeclatura dos Custo}

Para Martins (2010), Gastos refere-se ao valor da aquisição da matéria prima ou do serviços adquiridos ,gerando assim uma diminuição do ativo disponível da entidade , diminuição essa em razão da transferência ou promessa de entrega de dinheiro.

De acordo com Leone e Leone (2010), Gastos nada mais é do que as transações em que há ou a diminuição do disponível ou a assunção de um compromisso em troca de algum bem de investimento ou de consumo.Já na visão de Bonia (2010,p.15) "Gasto é o valor dos insumos adquiridos pela empresa, independentemente de terem sido utilizados ou não.”

Conforme Martins (2010), Desembolso , trata-se do pagamento resultante da compra de um produto, bem ou serviços,podendo ser realizado antecipadamente, durante ou após a entrada de um produto comprado, portanto defasada ou não momento do gasto.

Já investimento de acordo Bonia (2010), é aplicação de um valor em um bem adiquirido pela a organização para utilização futuras. 


\section{Custos e Despesa}

Segundo Martins (2010),Custo está relacionado com o gasto, sendo que é reconhecido no momento dos fatores de produção, isso é está ligado diretamente ao fator de produção de um bem ou de um serviço.

Ainda segundo Martins (2010),o custos refere-se ao material e mão de obra atibuído para fabricação do produto,este por sua vez,é de novo um investimento, já que fica em estoque como um ativo, isso é como um bem da organização até sua venda. Despesa para Martins (2010), está relacionada aos bens ou serviços consumidos direto ou indiretamente , isso é, são gatos necessários para a obtenção de receitas. Assim como no entendimento de Bonia (2010), despesa é valor que a empresa precisa desembolsar para continuar em funcionamento e não identificado na fabricação, assim segundo o mesmo autor as atividades fora do âmbito da fabricação, normalmente separados em administração, comerciais e financeiras.

\section{Perda e Desperdícios}

Perdas está associada ao bem ou Serviços consumido de forma anormal e involutária. Sendo que não está associada com a despesa e tão pouco com o custo, já que não é um sacrifício feito para a obtenção de receita. Conforme o mesmo autor as perdas são separadas dos custos por se trata de um consumo anormal da matéria prima, isso é bem ou serviço consumidos de forma anormal e involuntária (BONIA 2010).

Desperdícios é classificado como a produção de itens defeituosos, sendo uma movimentação desnecessária, a inspeção de qualidade e a capacidade ociosa, sendo um esforço econômico que não agrega valor ao produto e nem serve para suportar diretamente ao trabalho realizado ( BONIA 2010).

\section{Classificação dos Custos}

\section{Custos Diretos ou Indiretos}

custos diretos estão diretamente apropriados aos produtos, isso é ligado diretamente a linha de produção, tais como matéria-prima consumidas, embalagens, horas de mão de obra utilizada e até mesmo a quantidade de força consumida ( MARTINS 2010). 
Já os Custos Indiretos segundo o mesmo autor, referecem a condições em razão da tentativa de aplicação feita de maneira estimada e muitas vezes arbitraria, tais como pagamento de aluguel, salário da supervisão das chefias etc.

Para Brune e Famã (2012) ,os custos diretos são incluídos no custos dos produtos, já que refere-se aos materiais e mãos de obras usadas diretamente usadas na produção, dessa forma os custo indiretos não necessitam de critérios de rateios , para serem atribuídos aos produtos.

\section{Custos Fixos ou variável}

Para Martins (2010), Custos Fixos independem da linha de produção, já que é contada por mês , assim como o valor do aluguel do imóvel, já os custos variável ocorre de acordo com de acordo o volume de produção.

Os custos fixos possuem uma característica interessante: são variáveis quando calculadas dos unitariamente em função das economias de escalas. É importante destacar que a natureza de custos fixos ou variáves, está associadas ao volume produzidos e não ao tempo (BRUNI e 2012,p.12).

Ainda conforme Bruni (2010),os custos fixos são aqueles que independem do nível da atividade da empresa, ou seja não variam e não se alteram, caso aumentar o volume de produção. Por exemplo, o aluguel da empresa não sofre variação caso ela entre em recesso ou produza mais em algum determinado período. Já os custos variáveis estão diretamente ligados com a produção, isso é com o aumento da produção conseguentemente, aumentam os custos. Isso é estabelecido pela quantidade produzida de um determinado período como o gasto com embalagem e matéria prima (MEGLIORINI,2012)

\section{Métodos de Custeios}

De acordo com Bornia (2010), existe diversas visões sobre o custo dos produtos, por isso as organizações sentiu a necessidade de utilizar mais de um método de apropriação para chegar ao custo real, dessa forma surgiu a expressão método de custeio, para melhor analizar o funcionamento da empresa ,em relação ao processo de transformação de insumos em produtos, já que o métodos de custeio permite visualizar seus custos de forma mais evidente 
.uma vez que basicamente o objetivo da contabilidade de custos é a avaliação de estoque, permitindo assim demonstrar o resultado da empresa.

Bruni (2012), descreve neste Contexto, que os sistemas de custeios demonstra as proporções de como os custos estão registrados e serão computados no decorrer de todo o seu processo de produção, para que seja agregados ao valor do produtos todos os custos da linha de produção e as despesas envolvidas até a venda do mesmo.

\section{Custeio pelo Método por Absorção}

Custeio por Absorção é um sistema que compreende a apropriação dos custos que está relacionado a produção, desta forma todos gastos referentes a linha de produção até mesmo os relativos ao esforço que são atribuídos (MARTINS 2010).

Bornia (2010), Afirma que todos os custos fixos e variáveis precisão ser atribuídos aos produtos fabricados, já que está relacionado a linha de produção. Segundo o mesmo Autor o sistema de Custeio Pelo o método Absorção está relacionado com a avaliação dos estoque , ou seja todos os custos são calculados com o custo do produto.

Na Visão de Leone e Leone (2010, p.103) ”O critérios do custeio por absorção é um critério fiscal, pois é mais do agrado dos empresários e gerentes e, á primeira vista, está de acordo com os princípios fundamentais de contabilidade".

\section{Custeio Baseado em Atividades (ABC)}

Custeio baseado em atividades (ABC) é uma ferramenta capaz diminuir sensivelmente as modificações provocadas pelo rateio casuais dos custos indiretos,podendo ser aplicados aos custos diretos principalmente os relacionado a mão de obra (MARTINS 2010).

Segundo Leone e Leone, o critério de custeamento ABC surgiu da necessidade dos empresários ,em produzir informações mais precisas para dar suporte as diversas decisões gerenciais, onde através do mesmo será possível medir todos os custos, uma vez que torna-se á descriminado por cada atividade, assim ficará possível definir e agregar o valor aos produtos.

Os contadores que empregamos critério $\mathrm{ABC}$ dizem que as atividades que consumirem os recursos e as bases para proceder á alocação são chamadas de "direcionadores de recursos "os procedimentos são os mesmos e as limitações, portanto são as mesmas. Entretanto, uma vez que o critério ABC 
faz uma analise mais minuciosa das operações, as limitações tendem a crescer de importância" (LEONE ,2009,p.243).

\section{Custeio Variável}

O método de custeio variável possibilita a elaboração de um vantajoso indicador, para tomada de decisões das organizações, que é a margem de contribuição. Tendo em vista que este indicador é apontado como confiável, para as decisões de curto prazo, um vez que não se ocorre erro devido á alocação dos custos indiretos de fabricação, consequentemente através do custeio variável tornar-se possível visualizar que para o funcionamento de qualquer organização, tornase necessário os custos fixos, aqueles que não serão alterados , mesmo que ocorra aumento ou diminuição na produção isso é são proporcionais seus aumento ou diminuição. (ABBAS,GONÇALVES E LEONICE 2012). “O critério do custeio variável é muito útil para intervir no processo de planejamento e de tomada de decisões, até porque uma de suas potencialidades está centrada na análise da variabilidade das despesas e dos custos" (LEONE e LEONE, p.320).

Sendo assim segundo Costa (2012), os custos variáveis está diretamente ligado com a quantidade produzida, dessa forma o valor total oscila de acordo com o volume da produção. Bruni e Famã (2010), segue a mesma ideia já que reconhece que os custos variáveis tem seu valor total alterado em proporção com a produção , isso é quanto maior a produção maiores serão os custos variáveis .

O método de custeio variável é aplicado nas empresas como um método estratégico para auxiliar as decisões gerenciais, já que transfere para cada custo classificação específica, na condição de custos fixo ou custo variável, sendo o valor final do produto ou serviço a soma do custo variável distribuído pela a produção equivalente, onde os custos fixos serão atribuído diretamente no resultado do exercício.(OLIVEIRA ,COSTA 2010).

Por sua Vez tem uma grande importância no auxilio as decisões, dando suporte a seus usuários especialmente no que se refere a análise da margem de contribuição, permitindo desta forma a análise de custos volumes e preços (CORONETTI; SOUSA,2012).

Portanto, através da utilização do custeio variáveis é possível ver que, para o funcionamento de uma organização faz necessário os custos fixos, que não serão alterados com o aumento ou diminuição da produção ,pois não está diretamente ligados, visto a estrutura fixa da organização precisa está preparada para receber as clientelas ,sendo assim as decisões mais 
importantes correlacionada com os custos variáveis de acordo com (ABBAS, GONÇALVES e LEONICE, 2012).

Megliorini (2012), ressalta as vantagens existente na utilização do custeio variáveis: que é reconhecida através da correlação do custoslvolumellucro portanto essas informações é de suma importância para que a organização manter o planejamento referente sua lucratividade, uma vez que o processo não se utiliza rateios e através deste sistema é possível reconhecer os bens ou serviços mais rentáveis.

No entanto Stark (2007) enfatiza as desvantagens da utilização do sistema de custeio variáveis, uma vez que os custos variáveis corresponde uma significativa parte dos custos para fabricação do produto, e os custos fixos uma grande parcela, dessa forma ocorre uma perda de suma importância na análise dos preços, que possui uma grande influência relativa a mão de obra e matéria prima.

Assim sendo Leonice (2012) confirma que esse método não é permitido pela auditoria externas das entidades que tem capital aberto nem mesmo pela lei vigente referente ao imposto de renda.

\section{Gerenciamento e as Estratégias de Custos}

D do atual cenário competitivo e de constantes mudanças, as empresas necessitam cada vez mais tomar decisões acertadas para assim garantir sua longevidade, uma vez que tomar uma decisão correta passa ser a base de sucesso de qualquer organização, a gestão estratégica de custo passa ser uma excelente alternativa a ser utilizada no momento de tomada decisão, pois o pleno conhecimento e controle dos custos ,possibilidades a identificação dos desperdícios que oneram o custos do produto e dessa forma aumenta a lucratividade e conseguentemente a competividade da empresa, (PEREZ,OLIVEIRA E COSTA (2012).

O gerenciamento de custos é o processo de prever, destinar e monitorar os gastos , permitindo dessa forma que as empresas tenha uma visão do futuro , a ausência do controle e monitoramento dos custos é portanto uma das principais razões da pausa de grandes projetos, uma vez que a fase inicial de qualquer projeto é o planejamento, onde todas as despesas devem ser documentadas e rastreadas, para que tudo continue enquadrada dentro do orçamento inicial, BORNIA (2010). 
"Na guerra pela a sobrevivência no mundo dos negócios, é imprescindível o perfeito gerenciamento dos ganhos em uma extremidade, e dos custos e despesas na outra "PEREZ; OLIVEIRA e COSTA (2012).

A medida que se deseja implantar uma gestão estratégica de custos, faz-se necessário compreender e definir as dimensões do negócio, considerando a capacidade de geração de valor e resultados, uma vez que a estratégica de custos procura interligar as diversas atividades , buscando a interligação entre os fatores externos e internos, visando otimizar o processo de custos de cada produto, evitando dessa forma ameaças ambientais perante os pontos fortes e fracos, garantindo assim o sucesso do negócio (OLIVEIRA2013).

\section{Metodologia}

A pesquisa realizada neste estudo é de caráter bibliográfico, quando é elaborada a partir de material já publicado, tendo como objetivo colocar o pesquisado em contato direto com todo o material já escrito sobre o assunto da pesquisa. (PRODANOV; FREITAS , 2013).

Conforme os objetivos referem-se a uma pesquisa descritiva. Segundo GIL (1994), este tipo de pesquisa busca mostrar as características específicas sobre cada informação seja de carácter populacional ou de densidade demográfica peculiar do espaço.

Uma pesquisa exige um planejamento rigoroso quanto á definições de métodos e técnicas para coleta e análise de dados. É recomendável que nesse tipo de pesquisa se utilizem informações obtidas através de estudos exploratórios. Essas não so explicam a relação entre as variaves, como procuram determinar a natureza dessa relação, fundamentando com precisão os pressupostos ou hipóteses do objeto de estudo" (OLIVEIRA,2010, p. 68).

É caracterizado como pesquisa qualitativa por ter caráter exploratório que de acordo com Oliveira (2010, p.60) é "como sendo um estudo detalhado de um determinado fato, objeto, grupo de pessoas ou ator social e fenômenos da realidade”.

\section{Considerações Finais}

O presente Artigo teve como objetivo demonstrar a importância da contabilidade de custos para auxiliar as empresas nas tomadas de decisões para conseguir está a frente das 
grandes inovações diante do mercado competitivo, abordando assim como o sistema de custeio variável tem a capacidade de determinar os custos dos produtos e assim reduzir os desperdícios.

Apresentou-se alguns métodos de custeio, destacando-se a importância de se utilizar o sistema de custeio variável, indicando estratégica que auxiliem os gestores a tomarem as decisões acertadas, por ser uma ferramenta que ajuda diagnosticar a necessidade que as empresas tem para obter lucros.

Portanto, para descobrir se um investimento está trazendo retorno lucrativo, é indispensável que a empresa adote um sistema de custeamento para definir com maior precisão os custos de produção. Somente com estas informações será possível aplicar uma margem de lucro, que resulte em preços que sejam, simultaneamente competitivos no mercado e, que gerem lucro.

Foi demonstrado como o gerenciamento estratégico de custo pode auxiliar os gestores, mesmo com a complexidade existente, para definir quais os produtos traz mais retorno lucrativo, sem tomar decisões precipitadas que venham de encontro ao interesse comum, tanto com relação aos negócios quanto as necessidades dos clientes e fornecedores. A contabilidade de custo por suas vez dispõe de ferramentas que possibilitam os gestores, chegarem o mais próximo do objetivo de qualquer organização. A ideia é a busca da melhoria contínua no processo competitivo, gerando os lucros necessários a uma saudável convivência e, uma sustentabilidade duradoura.

\section{Referências}

ABBAS,Katia ;GONÇALVES ,Marguit Neumann;LEONCINE,Maury.Os Metodos de Custeios :Vantagens ,desvantagens e suas aplicabilidades nos diversos tipos de organização apresentada pela literatura 2012.disponivel em :http://ser.ufrgs.br/con Textolarticle/view/33487.Acesso 20 set.2018

BRUNI,AdrianoLeal;Fama,Rubens.Gestão de Custos e Formação de Preços: 6.ed.São Paulo:Atlas,2012

BORNIA, Antonio Cezar. Analise de Custos :Analise Gerencial de Custos :Aplicação em Empresas Modernas .3.ed. São Paulo :Atlas 2010.

CORONETTI,Jucimar;SOUSA,Marco Aurelio Batista. Os métodos de custeio utilizados nas maiores idustrias de Santa Catarina.Rev.Eletronica de Gestão org.maio e ago de 2012.Disponivelem: https://www.google.com.br/search?q=CORONETTI.Acesso em 18 set.2018 
CREPALDI,Silvio Aparecido.Curso Basico de Contabilidade.7.ed.São Paulo :Atlas,2013

GIL,Antonio Carlos .Como elaborar Projetos de pesquisa.4.ed.São Paulo :Atlas,2002.

LEONE,George S.G.;LEONE,Rodrigo José Guerra .Curso de Contabilidade de Custos .4.ed.São Paulo:Atlas,2010.

MARTINS,Eliseu.Contabilidade de Custos.10.ed.São Paulo:Atlas,2010

MEGLIORINI,EVANDIR.custos: análise e gestão.3.ed.São Paulo:Person Pretice Hall,2012.

OLIVEIRA Djalmas de Pinho Rebouças.Administração Estratégica na prática.8.ed.São Paulo:Atlas,2013

OLIVEIRA .M.M.Como Fazer Pesquisa Qualitativa .3.ed.Rev.E ampl.-Rio de Janeiro:Vozes, 2010.

PEREZ JUNIOR ,José hernandez,OLIVEIRA, Luiz Martins de ;COSTA,Rogerio Guedes Costa Gestão Estratática de Custos.8.ed.-São Paulo;Atlas,2012.

PEREZ JUNIOR ,José hernandez,OLIVEIRA, Luiz Martins de ;COSTA,Rogerio Guedes Costa Gestão Estratática de Custos.6.ed.-São Paulo;Atlas,2010.

PRODANOV,Cleber Cristiano;FREITAS,Ernani Cesar.Metodologia do trabalho Científico: métodos e técnicas de pesquisa e do trabalho acadêmico.2.Ed.Novo Hamburgo,Universidade de Feevale,2013.

STARK,José Antonio. Contbilidade de Custos.São Paulo:Pearson,2007.

MEGLIORINI,Evandir.Custos:Análise e Gestão.2.ed.São Paulo:Pearson,2012

HASHIMOTO, Marcos. Espírito Empreendedor nas organizações: Aumentando a competitividade através do intra-empreendedorismo. 3 ed. São Paulo, Saraiva, 2006.

Como citar este artigo (Formato ABNT):

SOUSA, Maria Edileide Ferreira de; ANASTÁCIO, Francisca Alexssandra de Macedo. Custeio Variável: Uma Ferramenta de Auxilio na Tomada de Decisão Gerencial. Id on Line Rev.Mult. Psic., 2019, vol.13, n.43, p. 310-321. ISSN: 1981-1179.

Recebido: 22/11/2018;

Aceito: $24 / 11 / 2018$ 